\title{
Total endoscopic left ventricle lipoma removal
}

\author{
Tom Langenaeken ${ }^{1 *} \mathbb{D}$, Aydin Basoglu ${ }^{2}$, Abdullah Kaya ${ }^{1}$ and Alaaddin Yilmaz ${ }^{1}$
}

\begin{abstract}
Background: Left ventricle (LV) lipoma is a very rare, benign cardiac tumor. Due to its rarity, LV lipoma is often misdiagnosed. Aspecific symptoms such as murmurs, arrhythmias, memory loss and palpitation may occur due to the mass effect.
\end{abstract}

Case presentation: We report a case report of a 42 year old woman who was found to have left ventricle mass after check-up for arrhytmia. By a fully endoscopic approach, the mass was successfully resected from the left ventricle without the need for sternotomy.

Conclusion: Total endoscopic removal of left ventricle lipoma's can be done safely and has several advantages to conventional sternotomy. Larger studies are needed to confirm this hypothesis.

Keywords: Cardiac lipoma, Radical resection, Minimally invasive, Clinical management, Case report

\section{Introduction}

Cardiac lipoma is a rare primary cardiac tumor. Origin in the left ventricle is seen in $33 \%$ of cases, with $57 \%$ of these cases the primary site being intracavity [1]. Almost two thirds of patients become symptomatic due to the mass effect. A broad variety of symptoms from chest pain to memory loss has been reported, though dyspnea is the most common. Diagnosis is made by ultrasonography supplemented by computed tomography $(\mathrm{CT})$ or magnetic resonance imaging (MRI). Radical resection is indicated in all cases of cardiac lipomas even when asymptomatic, due to the risk of overgrowth and infiltration in adjacent structures. Surgical resection is usually done by either full or partial resection. We propose a minimally invasive, non-sternotomy approach.

*Correspondence: tom.langenaeken@hotmail.com

1 Department of Cardiac Surgery, JESSA Hospitals Hasselt, Stadsomvaart 11, 3500 Hasselt, Belgium

Full list of author information is available at the end of the article

\section{Case presentation}

A 42-year-old woman was referred to our hospital due to detection of supraventricular arrhythmia during a dental procedure under general anesthesia. She was asymptomatic besides sporadic memory loss. Medical history was insignificant. Physical examination showed a body mass index (BMI) of $24 \mathrm{~kg} / \mathrm{cm}^{2}$, normal pulse of $80 \mathrm{bpm}$, blood pressure 130/90 $\mathrm{mmHg}$. She had no pathological murmurs nor any other abnormal findings. 12-lead electrocardiography (ECG) and exercise test were normal. Further evaluation by transesophageal ultrasound (US) and CT showed a globular mass attached to the apex of the left ventricle measuring $4.6 \times 3.6 \mathrm{~cm}$ (Fig. 1). No other abnormalities were found and echinococcus-serology was negative. Decision for minimally invasive resection was made.

After general anesthesia and standard draping, connection to the extracorporeal circulation (ECC) was made by femoral cannulation combined with jugular venous return. 3 trocars were placed in second to fourth intercostal space in the right axillary line. $1.5 \mathrm{~cm}$ utility port was placed in the third intercostal space. $5 \mathrm{~mm}$ thoracoscope was used for vision. Pericardium original author(s) and the source, provide a link to the Creative Commons licence, and indicate if changes were made. The images or other third party material in this article are included in the article's Creative Commons licence, unless indicated otherwise in a credit line to the material. If material is not included in the article's Creative Commons licence and your intended use is not permitted by statutory regulation or exceeds the permitted use, you will need to obtain permission directly from the copyright holder. To view a copy of this licence, visit http://creativecommons.org/licenses/by/4.0/. The Creative Commons Public Domain Dedication waiver (http://creativecommons.org/publicdomain/zero/1.0/) applies to the data made available in this article, unless otherwise stated in a credit line to the data. 


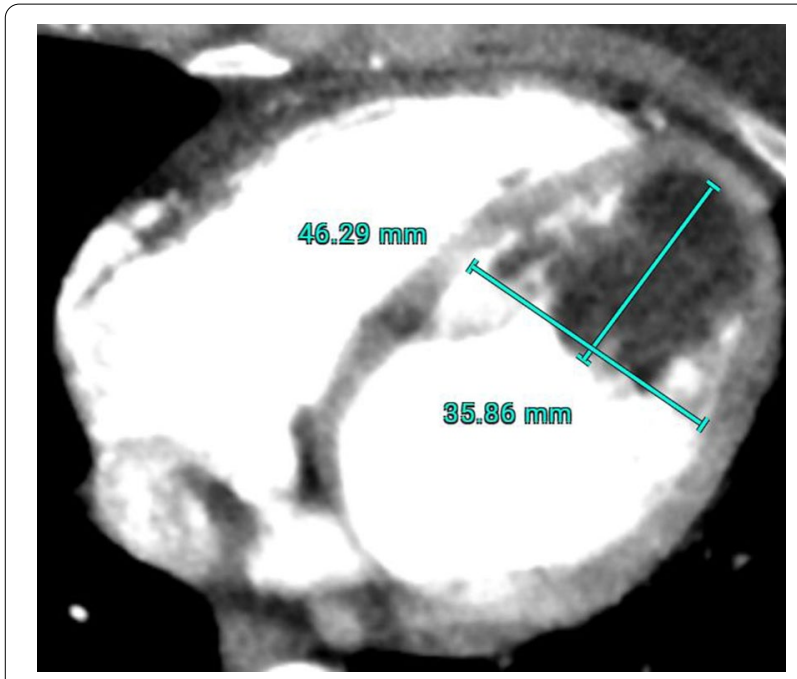

Fig. 1 CT image of the LV lipoma

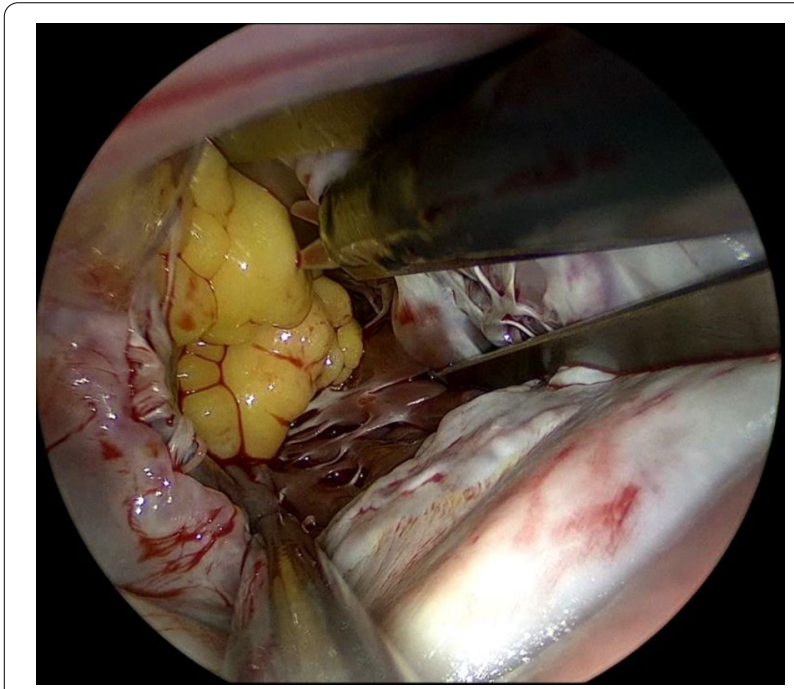

Fig. 2 Thoracoscopic view of the LV lipoma

was opened followed by aortic cross clamping and anterograde cardioplegia was given. Left atrium was accessed via Waterston's groove. Clearly visible behind the mitral valve is a lobulated, fatty mass with a broad base pedunculated to the apex of the left ventricle (Fig. 2). The mass has partial ingrowth in the left ventricular wall, but can be resected at a macroscopic safe margin using endoscopic scissors and forceps (Fig. 3). Attention was given to leaving enough ventricular wall intact for safe ventricular function. Inspection showed no residual lipoma tissue (Fig. 4). Left atrium was closed by continuous suture. Pericardium was closed

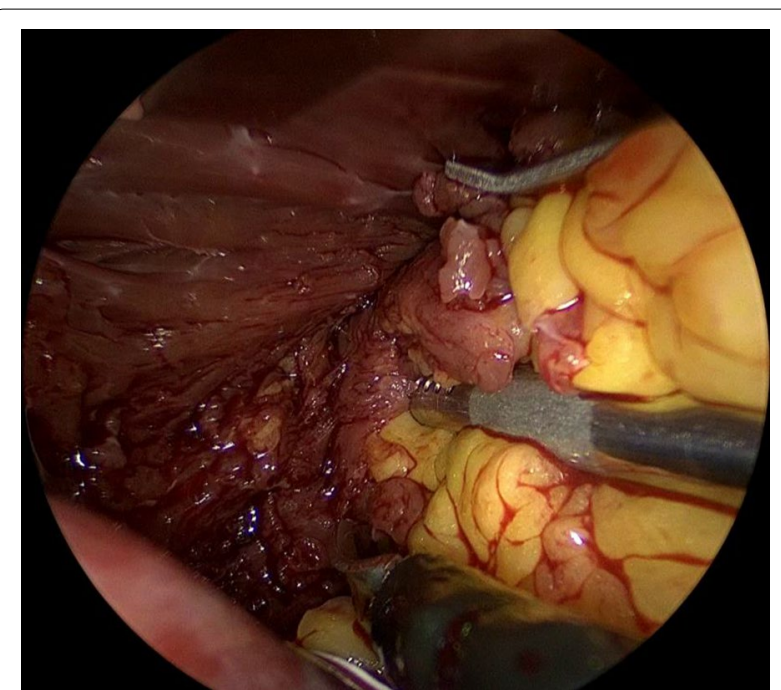

Fig. 3 Dissection of the LV lipoma from the LV wall

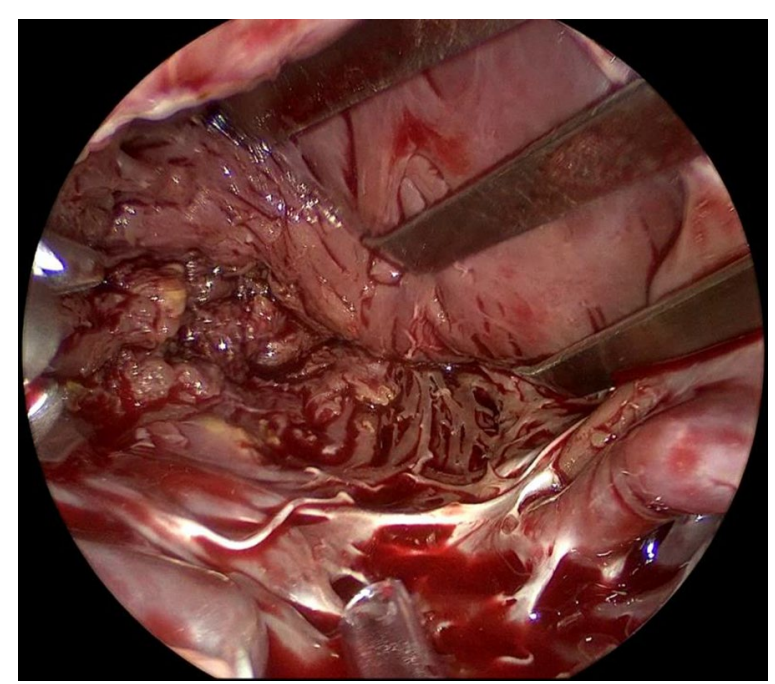

Fig. 4 Inspection of the LV wall after resection

and one thorax drain was left in the right pleural cavity. Patient was disconnected from the ECC and incisions were closed in layers.

Postoperative stay was uneventful and after 7 days patient was discharged. Histological examination was consistent with lipoma. Final measurements were $5.5 \times 3.5 \times 3.5 \mathrm{~cm}$. Further staining for liposarcoma was negative. Mouse double minute 2 homolog (MDM2) fluorescence in situ hybridization (FISH) was negative for malignant lipomatous tumor. Echocardiogram showed no signs of recurrence during a 2-month follow up period. 


\section{Discussion}

Up to date, no non-sternotomy minimally invasive approach has been reported. The technique described in this report allows adequate access to the left ventricle via the left atrium through the mitral valve by use of a utility port $(1.5 \mathrm{~cm})$ and 3 trocars entry points. Thorough inspection of the left ventricle is possible allowing for meticulous dissection of the LV lipoma from the left ventricular wall while keeping the lipoma itself intact, minimising the risk of embolization. Lipoma growth is from interior to exterior, hence an approach from inside the ventricle allows good differentiation between LV wall and lipoma. Sternotomy comorbidity is avoided allowing for lesser postoperative pain, faster mobilisation and recovery.

Literature about these rare cardiac tumors is mostly limited to isolated case reports, recently collected in a large systematic review [1]. Of all primary tumors, 0.2 to $0.4 \%$ are from cardiac origin. From these, only $8.4 \%$ are lipoma's mostly presenting in the $40-70$ year old age group with no gender predilection. Growth is slowly and asymptomatic in its early stages. Up to $57 \%$ of patients become symptomatic due to the mass effect on adjacent structures [1]. Echocardiogram is the preferred diagnostic tool LV lipomas: tumor shape and size, adjacent structures and interference with in- and outflow tracts can be evaluated. In addition, CT or MRI can further objectivate tumor density, blood supply and (extra)cardiac invasion. Postoperative histological examination is crucial for diagnosis confirmation. MDM2 FISH test is needed in adjunct to histology to distinguish between lipoma and atypical lipomatous tumor [2].

Despite no official guideline for treatment of lipoma, current practice is surgical resection by either partial or full sternotomy. Some have reported thoracoscopic techniques, though sternotomy was still needed $[3,4]$. Other approaches such as by ventriculotomy have also been described, though we deem this approach high risk due to weakening of the ventricular wall and possible lesion of the coronary arteries [5].

\section{Conclusion}

LV lipoma is a very rare, benign cardiac tumor. Once patients become symptomatic, resection should be considered. Standard surgical approach is by sternotomy. We think a fully endoscopic approach is feasible and beneficial for most patients.

\section{Abbreviations}

LV: Left ventricle; CT: Computed tomography; MRI: Magnetic resonance imaging; BMI: Body mass index; ECG: Electrocardiography; US: Ultrasound; MDM2: Mouse double minute 2 homolog; FISH: Fluorescence in situ hybridization.

\section{Acknowledgements}

Not applicable.

Authors' contributions

TL: conceptualisation, drafting article. AY: critical revision of the article. AB: critical revision of the article. AK: critical revision of the article. All authors read and approved the final manuscript.

Funding

Not applicable.

Availability of data and materials

All data is available.

\section{Declarations}

Ethics approval and consent to participate

Patient consent for publication was obtained. Publication of this case report was approved by the Ethics Committee Research JESSA Hospitals Hasselt.

\section{Consent for publication}

Written patient's approval for publication was obtained and can be presented if needed.

\section{Competing interests}

None to declare.

\section{Author details}

'Department of Cardiac Surgery, JESSA Hospitals Hasselt, Stadsomvaart 11, 3500 Hasselt, Belgium. ${ }^{2}$ Department of Cardiology, MOL Hospitals, Mol, Belgium.

Received: 26 May 2021 Accepted: 28 July 2021

Published online: 04 August 2021

\section{References}

1. Shu S, Wang J, Zheng C. From pathogenesis to treatment, a systemic review of cardiac lipoma. 2021;16. J Cardiothor Surg. Available from: / pmc/articles/PMC7788760/.

2. Kashima T, Halai D, Ye H, Hing SN, Delaney D, Pollock R, et al. Sensitivity of MDM2 amplification and unexpected multiple faint alphoid 12 (alpha 12 satellite sequences) signals in atypical lipomatous tumor. Mod Pathol. 2012;25(10):1384-96

3. Kim SW. Hong JM, Kim DW. Left ventricular apical lipoma resected under the guidance of a mediastinoscope. Ann Thorac Surg. 2010:90(3):1019-21.

4. Sun X, Liu G, Kim H, Sun W. Left ventricular lipoma resected using thoracoscope-assisted limited sternotomy: a case report and literature review, vol. 97, Medicine (United States); 2018. Lippincott Williams and Wilkins. Available from: /pmc/articles/PMC6081152/.

5. Shamsi F, Bajwa G, Ghalib H. Left ventricular lipoma a rare case, case report. J Cardiothorac Surg. 2020;15(1):85.

\section{Publisher's Note}

Springer Nature remains neutral with regard to jurisdictional claims in published maps and institutional affiliations. 